\title{
Should myopes have routine axial length measurements before retrobulbar or peribulbar injections?
}

Knapp was the first person to report using local anaesthesia for eye surgery in 1884 when he carried out an enucleation following a retrobulbar injection of cocaine. ${ }^{1}$

Retrobulbar and peribulbar injections are now routine ophthalmic procedures that are commonly performed to induce anaesthesia and akinesia. In institutions carrying out day case surgery this is often the principal technique of anaesthesia.

Complications of local anaesthesia for ophthalmic surgery are well recognised. ${ }^{2}$ Hay et al described 23 cases of globe perforation, 12 after retrobulbar and 11 after peribulbar injections. ${ }^{3}$ Although the incidences of globe penetration or perforation are rare, figures vary from three in 4000 retrobulbar blocks ${ }^{4}$ to one in 16224 peribulbar blocks, ${ }^{5}$ there are preoperative measures that, if adopted, can further reduce this risk.

Establishing a rapport with patients reduces their anxiety and stress, thereby lowering arterial blood pressure and improving patient cooperation. The use of warmed anaesthetic solutions has been shown to be more comfortable for the patient. There appears to be no significant difference in the complication rate whether a sharp or a blunt needle is used for the injection ${ }^{6}$ although it is generally agreed that the incidence of globe perforation is reduced if the needle length is less than $3 \mathrm{~cm} .{ }^{2}$ A good knowledge of orbital anatomy is important whether it is the anaesthetist or ophthalmologist giving the anaesthetic. Globes with an axial length greater than $26 \mathrm{~mm}$ are particularly at risk. These tend to be myopic eyes which are not only larger but also have thinner sclera. ${ }^{47}$ Preoperative axial length measurements can identify these patients and alert both the anaesthetist and surgeon. Ultrasound biometry is routine for patients with cataracts as part of the intraocular lens implant power calculation but we have not read any recommendation that this should be performed for patients undergoing other forms of ocular surgery under local anaesthesia. Myopes undergoing trabeculectomy or vitrectomy, for instance, are presumably exposed to the same risks of globe perforation. Perhaps the umbrella should be further extended to include myopes receiving retrobulbar injections for other procedures in view of reports of needle penetration following retrobulbar steroid injections. ${ }^{89}$ We are not aware of any publications concerning this issue and suggest that there may be a rationale for axial length measurements in all myopes undergoing peribulbar or retrobulbar injections whether for the administration of medications or for anaesthetic purposes.

\section{AMANDA J CHURCHILL} TEIFION E JAMES

Department of Ophthalmology, St James's University Hospital, Leeds LS9 7TF

VERITY LACEY

Department of Anaesthetics, St James's University Hospital, Leeds LS9 7TF

1 Altman M, Albert DM, Fournier GA. Cocaine's use in ophthalmology: our 100-year heritage. Surv Ophthalmol 1985;29:300-6.

2 Rubin AP. Complications of local anaesthesia for ophthalmic surgery. $\mathrm{Br} \mathcal{F}$ Anaesth 1995;75:93-6.

3 Hay A, Flynn HW Jr, Hoffman JI, Rivera AH. Needle penetration of the globe during retrobulbar and peribulbar injections. Ophthalmology 1991;98: 1017-24.

4 Ramsay RC, Knobloch WH. Ocular perforation following retrobulbar anaesthesia for retinal detachment surgery. $A m \mathcal{F}$ Ophthalmol 1978;86:61-4.

5 Davis DB II, Mandel MR. Efficacy and complication rate of 16,224 Davis DB II, Mandel MR. Efficacy and complication rate of 16,224
consecutive peribulbar blocks. A prospective multi-centre study. $\mathcal{~ C a t a r a c t}$ consecutive peribulbar blocks.

6 Refract Surg 1994;20:327-37. RL. Perforating ocular injuries caused by anaesthetic personnel. Ophthalmology 1991;98:1011-6.

Feibel RM. Current concepts in retrobulbar anaesthesia. Surv Ophthalmo 1985;30:102-10.

8 Schlaegel TF Jr, Wilson FM. Accidental intraocular injection of depot corticosteroids. Trans Am Acad Ophthalmol Otolaryngol 1974;78:OP847-55.

9 Giles CL. Bulbar perforation during periocular injection of corticosteroids. Am $\mathcal{f}$ Ophthalmol 1974;77:438-41. 